\title{
A Review on Mobile and Sensor Networks Innovations in Intelligent Transportation Systems
}

\author{
Emad Felemban', Adil A. Sheikh ${ }^{2}$ \\ ${ }^{1}$ Department of Computer Engineering \& Simplicity Labs, Umm Al-Qura University, Makkah, Saudi Arabia \\ ${ }^{2}$ Science and Technology Unit \& Simplicity Labs, Umm Al-Qura University, Makkah, Saudi Arabia \\ Email: eafelemban@uqu.edu.sa, aasheikh@uqu.edu.sa
}

Received 8 May 2014; revised 4 June 2014; accepted 25 June 2014

Copyright @ 2014 by authors and Scientific Research Publishing Inc.

This work is licensed under the Creative Commons Attribution International License (CC BY). http://creativecommons.org/licenses/by/4.0/

c) (7) Open Access

\begin{abstract}
Rapid developments of mobile technologies, data acquisition and big data analytics, and their integration with critical application domains such as transportation systems have the potential to produce more efficient, real-time, intelligent and safe transportation infrastructure. To increase the quality of transportation services, wireless sensor networks, mobile phones, crowd sourcing, RFID and Bluetooth technologies are being used. We surveyed innovations that were transformed from ideas in research labs into commercial systems in practical use. In this paper, we present some innovative mobile technologies, services and platforms that are being used in modern transportation applications including traffic data acquisition, traffic management and control, route optimizations, infrastructure redesign, road safety and enhancing user experience.
\end{abstract}

\section{Keywords}

Intelligent Transportation Systems, Mobile Innovation, Wireless Sensor Networks

\section{Introduction}

In the last couple decades, there have been rapid developments in the fields of mobile technologies, data acquisition and data analytics. The number of mobile phone users all over the world has increased tremendously over the last decade. In some countries, the number of mobile phones exceeds the population. With the advent of smartphones, crowd sourcing has been made possible. Likewise, data acquisition and analysis techniques have evolved rapidly with the swift increase in processing capabilities. We surveyed the technologies that had been developed in the last two decades that are now being used in making our everyday driving and travel experience 
better. We also surveyed the current research work being done as well as commercial projects to present a summary of works in the field of intelligent transportation systems (ITS).

This paper is distributed as follows. Section II, presents the challenges faced by drivers and how they can be addressed by ITS. In Section III, we present the evolution of sensor technologies and research work done in ITS. Then, in Section IV, we conclude the paper by highlighting current commercial projects in ITS.

\section{Challenges That Can Be Solved by ITS}

A city is said to be smart if investments in human and social capital and traditional and modern communication infrastructure fuel sustainable economic development and a high quality of life, with a wise management of natural resources, through participatory action and engagement [1]. Intelligent transportation systems are advanced applications of smart cities which aim to provide innovative services relating to different modes of transport and traffic management in order to enable various users to be better informed and make safer, more coordinated, and "smarter" use of transport networks. There are many challenges that can be overcome by ITS. This section briefly summarizes them.

\subsection{Traffic Congestion}

Traffic congestion occurs as use of a road increases. It is characterized by slower speeds, longer trip times and increased vehicular queuing. Congestion is caused by three main reasons [2].

1) Traffic incidents such as accidents, construction activities, bad weather, etc.

2) Fluctuations in normal traffic because of increased in number of cars on the road due to special events or otherwise.

3) Physical conditions of the road such as bottlenecks, etc.

The first step towards solving this challenge is to count vehicles on a road segment. ITS minimizes traffic congestion by informing driver, traffic management and road planning departments about live traffic conditions as well as traffic patterns. Driver can plan their route using less congested roads. ITS helps traffic management and city planners in planning better road networks.

\subsection{Accidents and Emergency Conditions}

According to [3], 1.24 million deaths have been reported worldwide due to road accidents. Causes include intoxicated drivers, over speeding, road side distractions and bad weather. ITS solutions help to identify driver behavior have been researched on by [4].

\subsection{Emission and Environmental Pollution}

Auto-emission is one of the biggest contributors of $\mathrm{CO}_{2}, \mathrm{CO}, \mathrm{NO}_{\mathrm{x}}$ and un-burned hydrocarbons. The main reasons are lack of engine tuning, inconsistencies in engine health checks and adulteration in fuel. Advances in sensor technology have made it possible to detect the presence of such pollutants through the vehicle exhaust. City planners are using ITS to identify vehicles whose engine health has deteriorated. Regular health checks have been introduced by traffic authorities enforcing vehicle owners to maintain a healthy vehicle engine.

\subsection{Finding a Parking Space}

According to [5], one of the major factors causing traffic is caused by drivers looking for a parking space. Various solutions have been proposed that guide the driver in finding a parking space [5]-[9].

\subsection{Route Planning}

Drivers want to take their vehicles from point A to point B, optimally. Change in traffic patterns and unforeseen obstacles such as accidents, road blocks, traffic jams, constructions work hinder this requirement. This causes waste of fuel and time. Global Positioning System (GPS) helps identify ones location on a map. ITS uses GPS and Vehicular Ad hoc networks (VANET) [10] concepts to assist drivers in making informed routing decisions [11].

The challenges presented above can be tabularized into three classes: enhancing user experience, efficiently 
managing traffic and road safety. Table 1 summarizes them.

\section{Research on WSN for ITS}

This section highlights the research done in academia in the field of ITS.

Researchers at MIT built a sensor package [12] in 1999 that counts cars, measures average speed, and detects ice or water on the road. Figure 1 shows their package. They detect vehicles using perturbations in earth's magnetic field due to vehicles. They discuss various approaches to count cars. These are in-road inductive loops, probe vehicles in traffic, use of magnetic sensors, use of intelligent road studs, some machine vision techniques (with problems) and use of data from cellular network. Their work targets solving the efficient traffic management and road safety challenge by providing a framework to collect traffic data.

Chen et al. [13] propose a WSN-based transportation information collection and communication system. They designed and prototyped hardware and software WSN modules. They also define the components of ITS as surveillance sub-system, strategy sub-system, execution sub-system and communication sub-system as shown in Figure 2. They created three nodes types: vehicle unit (mobile nodes), roadside unit (static nodes) and intersection unit (sink). Their work targets solving the efficient traffic management and road safety challenge by providing a framework to collect traffic data.

Authors of [14] discuss a VANET that includes roadside gateway nodes. Their inter-vehicle communication (IVC) protocol has two types of communication; periodic and alert based. Their aim is to increase safety. They verified their algorithm using Matlab and then NS-2 simulators and finally implemented on hardware using small remote control cars. They also highlight a few other VANET implementations. Their work targets solving the efficient traffic management and road safety challenge by providing a framework to collect traffic data.

Other researchers [15] present a traffic monitoring system implemented through WSN with the aim of a flexible, robust, low-cost and low-maintenance wireless solution for obtaining traffic-related data for generating safety warnings at black spots along the road network. Their WSN consists of one Gateway Node (GN) and n Sensor Nodes (SNs) deployed along the roadside according to an approximately linear topology.

Each SN is able to monitor a section of road, collecting parameters such as vehicle count, speed and direction.

Table 1. Classes of transportation challenges.

\begin{tabular}{ccc}
\hline Efficient Traffic Management & Road Safety & User Experience Enhancement \\
\hline Counting Vehicles on Road & Avoiding Accidents & Finding a Parking Space \\
Automatic Traffic Signal Control & Detection of Emergency Conditions & Routing Planning \\
Detection of Emission \& Environmental Pollution & \\
\hline
\end{tabular}

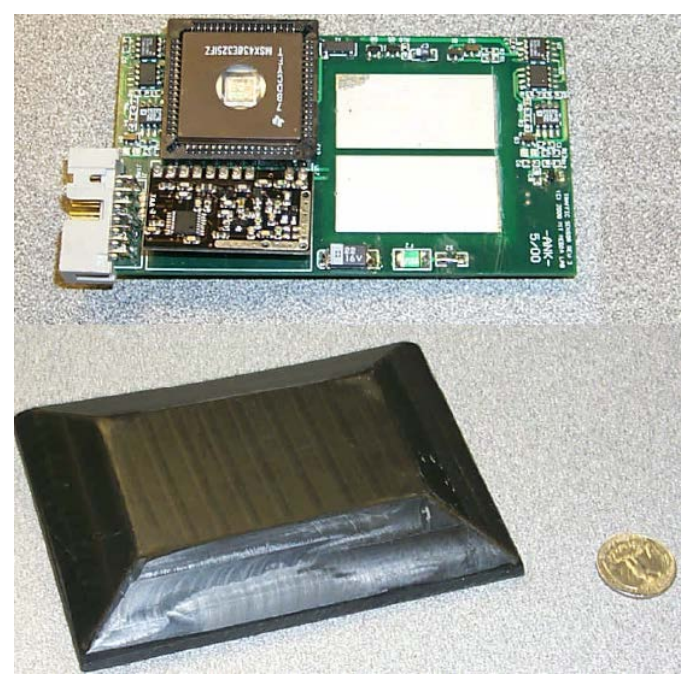

Figure 1. MIT’s sensor package [12]. 

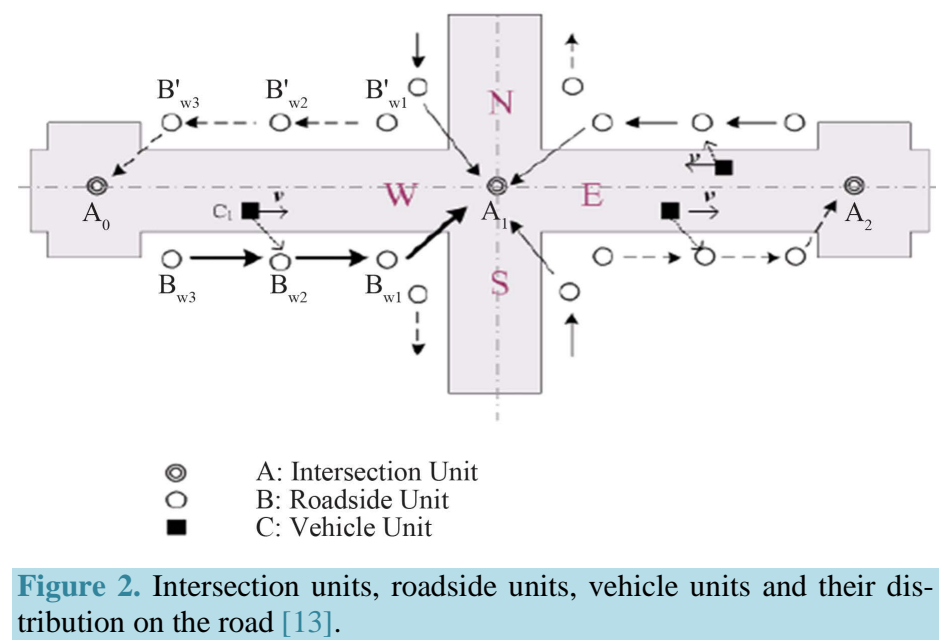

Data from the SNs is collected by the GN and delivered to a Road Side Unit (RSU) responsible for fusing it with traffic-related data generated by alternative sources. Their system has been tested under a number of real use-case scenarios. Their paper contains implementation details using TelosB [16]. Their work targets solving the efficient traffic management challenge by providing a framework to collect traffic data.

Authors of [17] present the requirements for an efficient WSN architecture for ITSs. They surveyed WSN architectures and listed a big number of ITS projects. They have categorized them into monitoring parking lots, traffic management and control, and traffic estimation. They discuss the key factors that drive design of WSN for ITS. Their work targets solving the efficient traffic management challenge and enhancing user experience by providing an efficient WSN architecture.

Tao et al. [18] focus on comprehensive analysis of network topology, energy saving and stability and reliability. They propose hardware design of sensor network node and network protocols suitable for urban public transport system. Online travel buses can be monitored in real-time, to achieve the purpose of intelligent management. This system has higher cost performance compare with the current GPS used in public transit system. They present their solution but no comparison is made with existing solutions. Their work targets solving the efficient traffic management challenge by providing a framework to collect traffic data.

Authors of [19] present an efficient architecture to increase the safety of road travel using WSN and Bluetooth. We also discuss the ad-hoc network formation between vehicles and data exchange sensed by sensors. Their simulation results show that Bluetooth and sensor networks can be used collaboratively to increase the safety of road travel. They also highlight some design parameters for ITS. Their work targets at solving the road safety challenge by providing a data collection framework based on WSN and Bluetooth.

Selvarajah et al. [20] talk about heterogeneous wireless sensor network for transportation system applications. In their paper, WSN applications in ITS, the transport systems and the use middleware to integrate heterogeneous wireless cooperative objects (WICOs) are discussed. They describe the EMMA project and its hierarchical approach and communication technologies. An overview of wireless sensor networks middleware and components of the EMMA middleware is also presented. They describe the different hardware platforms which are used as wireless cooperating objects in the prototype applications. Three applications for each hierarchical level and an inter-hierarchical level application are given with results obtained from the experiments in investigating the feasibility of utilizing EMMA middleware in real transport system applications. Their network hierarchy is depicted in Figure 3.

In their extension paper [21], Selvarajah et al. provide a good comparison of wireless technologies and a few more ITS projects in their extension paper. Both of their works target solving the efficient traffic management challenge by providing a framework to collect traffic data using heterogeneous WSN.

Karpis et al. [22] further analyze the possibilities of exploitation the technology of WSN in ITS. Detailed description of sensor node designed for sensing intensity of magnetic field and acceleration is provided. As an example, the proposed sensor is used to sense the speed of moving vehicles and to classify the vehicles according their estimated length. Their work targets at solving the efficient traffic management challenge by counting vehicles and classifying them based on their length profile. 
Claudel et al. [23] at the King Abdullah University of Science and Technology (KAUST) use passive infrared and ultrasonic sensor to classify cars and detect flooding on streets. Their device can be seen in Figure 4. Their work targets solving the efficient traffic management and road safety challenges by counting vehicles, classifying them and detecting water on road.

\section{ITS Solutions in Market}

This section briefly summarizes the ITS solutions in the market.

Masarak [24] is a suite of intelligent transportation, road safety and logistics services fully developed in Qatar by Qatar Mobility Innovation Center (QMIC). Masarak relies on collecting real-time traffic data from various sources then passes the traffic raw data through their Labeeb platform to provide real-time traffic information. This information is used by the many applications and services in Masarak, such as iTrafficMon (traffic monitoring in real-time), iTripPlanner (trip planning service using real-time information), iFleet (intelligent fleet manager), iDispatch, iChildSafety, and others. Their graphical user interface can be seen in Figure 5. Their suite of products target efficient traffic management, road safety as well as enhancing user experience.

Hawa'ak [25] is another rich and flexible platform by QMIC that supports real-time monitoring of air quality and other environment conditions. It allows users to access such information through innovative applications that can be accessed through multiple channels including mobile delivery, web, SMS, and voice interaction. This platform provides enhancements to user experience.

Labeeb [26] is QMIC's proprietary intelligent sensing and Machine-to-Machine (M2M) services platform that collects raw data from multiple sources with different formats and capabilities then transforms it into very meaningful and useful information. This information is then used to develop intelligent services and applications that address the needs of different user segments. This product provides a framework to collect data for efficient

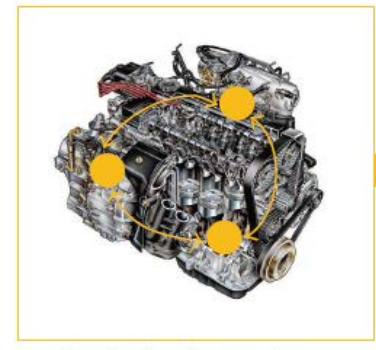

Engine level networks

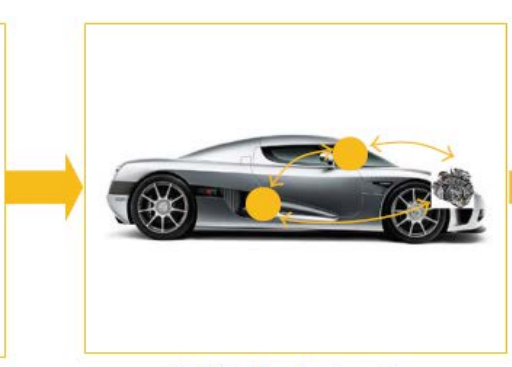

Vehicle level networks

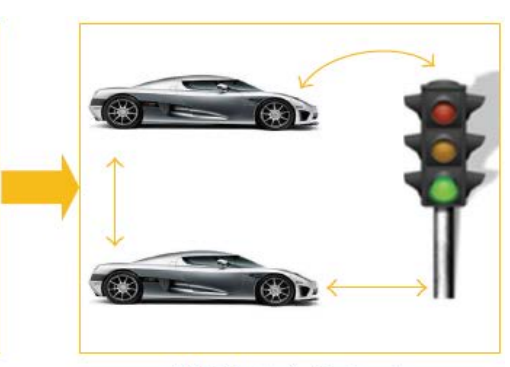

Vehicle-to-infrastructure level networks

\section{Figure 3. EMMA hierarchical network [20].}
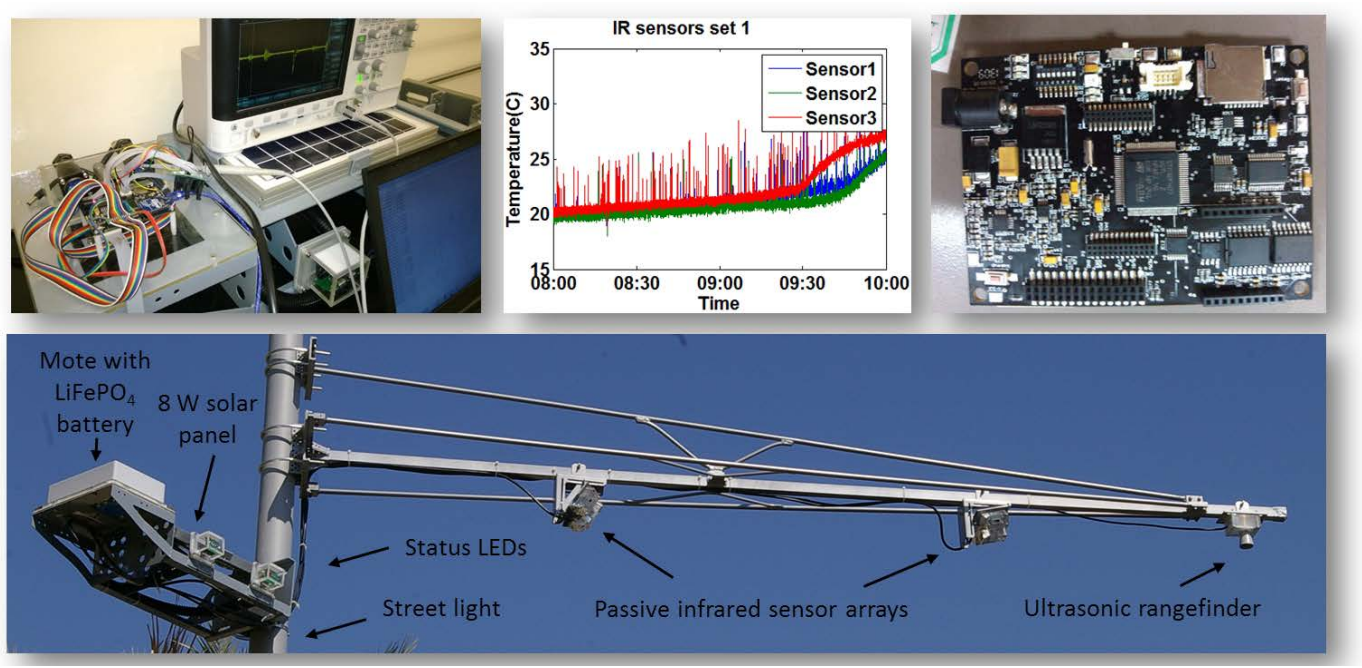

Figure 4. Passive IR and ultrasonic solution by KAUST [23]. 


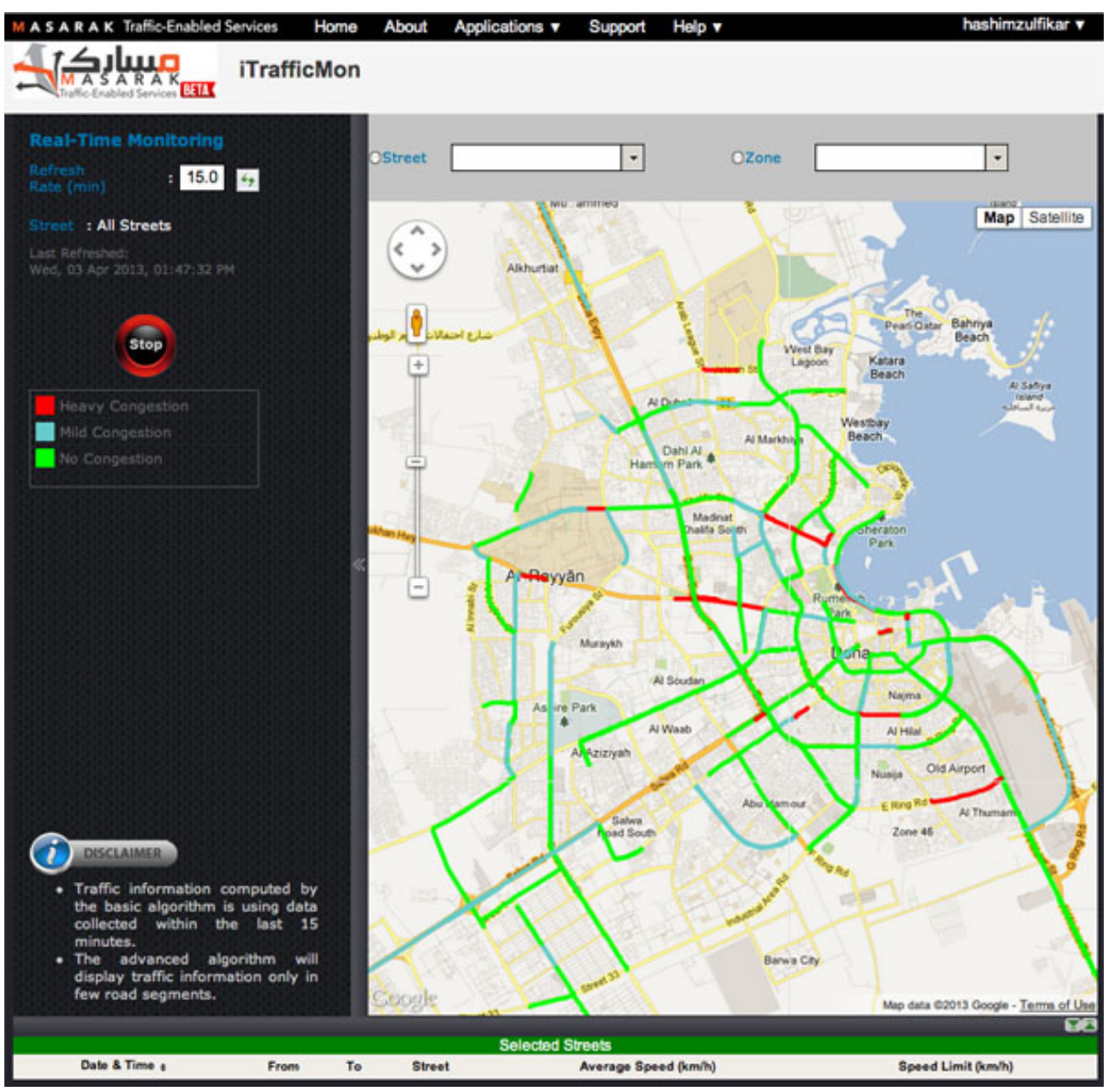

Figure 5. Masarak by QMIC [24].

traffic management.

Dash [27] by Dashmobile (Figure 6) connects the smartphone to the car with a simple, low-cost device. The device interfaces with the car's CAN-bus [28] to get access to On-Board Diagnostics (OBD). The device connects the smartphone by pairing via Bluetooth. Dash provides real-time diagnostics on the vehicle's performance, from 'Check Engine Light' diagnostics to fuel level. They also provide information on road conditions and driving behavior, to enhance driving. This product enhances user experience on the road.

San Francisco's Municipal Transportation Agency established SFpark [7] to use new technologies and policies to improve parking in San Francisco by reducing traffic by helping drivers find parking benefits everyone. SFpark works by using smart pricing so that drivers can quickly find open spaces. This project provides an infrastructure to improve user experience.

Safe Road Trains for the Environment (SARTRE) [29] is a European Commission-funded project to investigate and trial technologies and strategies for the safe platooning of road vehicles, a transportation concept in which several vehicles are electronically linked together in a "road train" as depicted in Figure 7, with only the lead driver in active control. The research and development was carried out by several European auto manufactures with Volvo at the lead. The SARTRE platooning system envisages a platoon of up to eight vehicles linked electronically, with the lead vehicle controlled by a professional driver, controlling in turn those following, as slave vehicles. Aimed at commuters in cars, but also possibly commercial vehicles and buses, drivers would be able to join and leave the platoon at will. To keep costs down, the technology for the system is to be achieved through off the shelf components, and specifically without requiring costly changes to highway infrastructure. This project provides means to efficiently manage traffic as well as enhance user experience while driving autonomously in a road train. 
Park4U [8] by Valeo is an assisted-parking system that uses several sensors and other components to help drivers squeeze their vehicles into even the tightest parking spots. The car parks itself without the driver's intervention. This product focuses on enhancing user experience with the help of technology to automatically park a vehicle.

BMW's Park Assistant is part of its Connected Drive [9] initiative. The Park Assistant searches for a suitable parking space. At speeds up to $35 \mathrm{~km} / \mathrm{h}$ and a maximum distance of $1.5 \mathrm{~m}$ to the row of parked cars at the side, the ultrasonic sensors of your BMW measure potential parking spots, which the system then displays to driver. When the driver selects a parking space, the system then selects the gear on its own, guides the steering and automatically accelerates or brakes. This product also focuses on enhancing user experience using automatic parking technology.

\section{Conclusion}

In this paper, firstly, we present challenges that can be solved by ITS and classify them. Secondly, we present a review of research projects and market solutions that solve these challenges. Finally in Table 2, we conclude the paper by providing a distribution of research projects and market solutions into the transportation challenge classes.

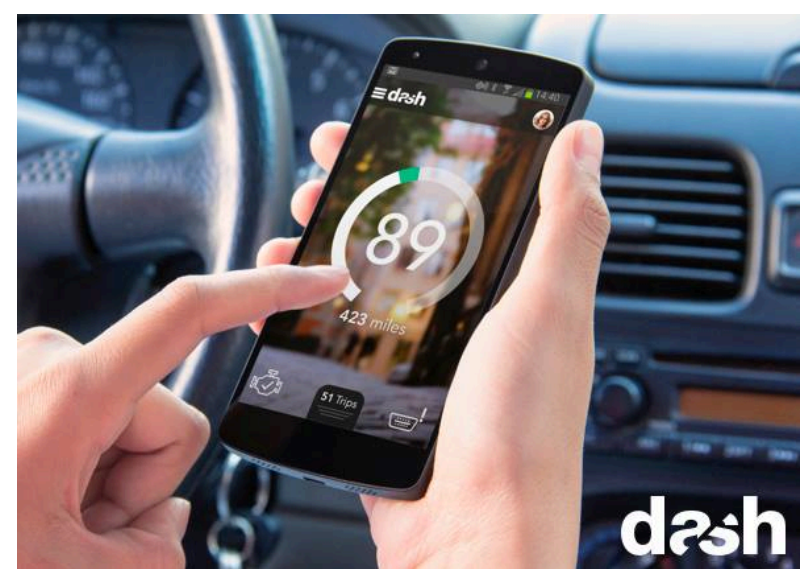

Figure 6. Dash by dashmobile [27].

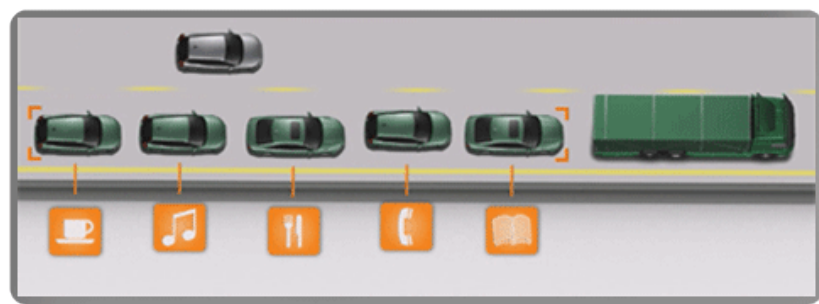

Figure 7. Road train by SARTRE [29].

Table 2. Projects and market solutions distribution into transportation challenges classes.

\begin{tabular}{cccc}
\hline & $\begin{array}{c}\text { Efficient Traffic } \\
\text { Management }\end{array}$ & Road Safety & $\begin{array}{c}\text { User Experience } \\
\text { Enhancement }\end{array}$ \\
\hline Research Projects & {$[12][13][14]$} & & \\
& {$[15][16][17]$} & {$[12][13][14]$} & {$[17]$} \\
Market Solutions & {$[22][23][21]$} & {$[15][19][23]$} & \\
& {$[24][26][29]$} & & {$[7][8][9][24]$} \\
\hline
\end{tabular}




\section{Acknowledgements}

This work has been supported by Simplicity Labs and The Transportation and Crowd Management Center of Research Excellence (TCM-CoRE) in Umm Al-Qura University, Makkah, Saudi Arabia.

\section{References}

[1] Caragliu, A., Del Bo, C. and Nijkamp, P. (2009) Smart Cities in Europe. Proceedings of the 3rd Central European Conference in Regional Science-CERS 2009, Košice, 7-9 October 2009, 49-59.

[2] United States Department of Transportation (2005) Traffic Congestion and Reliability: Trends and Advanced Strategies for Congestion Mitigation. Cambridge Systematics, Inc. and Texas Transportation Institute. http://www.ops.fhwa.dot.gov/congestion report/

[3] Ezell, S. (2010) Intelligent Transportation Systems. Information Technology and Innovation Foundation. www.itif.org/files/2010-1-27-ITS Leadership.pdf

[4] Al-Sultan, S., Al-Bayatti, A.H. and Zedan, H. (2013) Context-Aware Driver Behavior Detection System in Intelligent Transportation Systems. IEEE Transactions on Vehicular Technology, 62, 4264-4275. http://dx.doi.org/10.1109/TVT.2013.2263400

[5] Wang, H.W. and He, W.B. (2011) A Reservation-based Smart Parking System. Proceedings of the IEEE Conference on Computer Communications Workshops (INFOCOM WKSHPS 2011), Shanghai, 10-15 April 2011, 690-695.

[6] Sakai, A., Mizuno, K., Sugimoto, T. and Okuda, T. (1995) Parking Guidance and Information Systems. Proceedings of 6th International Vehicle Navigation and Information Systems Conference, Seattle, 30 July-2 August 1995, 478-485.

[7] SFPark Project (2014) San Francisco Municipal Transportation Agency. http://sfpark.org

[8] Park4U (2014) Parking Assistant by Valeo. http://www.valeo.com/en/

[9] BMW Connected Drive (2014) http://www.bmw.com/com/en/insights/technology/connecteddrive/2013/index.html

[10] Lee, S.-H. and Cho, D.-H. (2000) A New Adaptive Routing Scheme Based on the Traffic Characteristics in Mobile Ad Hoc Networks. Proceedings of 52nd Vehicular Technology Conference, 6, 2911-2915. http://dx.doi.org/10.1109/VETECF.2000.886849

[11] Ambrose, J.K., Bukovsky, D.J., Sedlak, T.J. and Goeden, S.J. (2009) Developing a Travel Route Planner Accounting for Traffic Variability. Proceedings of Systems and Information Engineering Design Symposium SIEDS’09, Charlottesville, 24-24 April 2009, 264-268.

[12] Knaian, A.N. (2000) A Wireless Sensor Network for Smart Roadbeds and Intelligent Transportation Systems. Ph.D. Thesis, Department of Electrical Engineering and Computer Science, MIT.

[13] Chen, W.J., Chen, L.F., Chen, Z.L. and Tu, S.L. (2006) WITS: A Wireless Sensor Network for Intelligent Transportation System. Proceedings of 1st International Multi-Symposiums on Computer and Computational Sciences, 2, 635641.

[14] Sawant, H., Tan, J.D. and Yang, Q.Y. (2004) A Sensor Networked Approach for Intelligent Transportation Systems. Proceedings of IEEE International Conference on Intelligent Robots and Systems, 2, 1796-1801.

[15] Franceschinis, M., Gioanola, L., Messere, M., Tomasi, R., Spirito, M.A. and Civera, P. (2009) Wireless Sensor Networks for Intelligent Transportation Systems. Proceedings of IEEE 69th Vehicular Technology Conference, Barcelona, 26-29 April 2009, 1-5.

[16] Polastre, J., Szewczyk, R. and Culler, D. (2005) TELOS: Enabling Ultra-Low Power Wireless Research. Proceedings of the 4th IEEE International Symposium on Information Processing in Sensor Networks, (IPSN’05), 15 April 2005, 364-369. http://dx.doi.org/10.1109/IPSN.2005.1440950

[17] Khanafer, M., Guennoun, M. and Mouftah, H.T. (2009) WSN Architectures for Intelligent Transportation Systems. Proceedings of 3rd International Conference on New Technologies, Mobility and Security (NTMS2009), 20-23 December 2009, 1-8.

[18] Tao, H.Q., Liu, W.C. and Ma, S.B. (2010) Intelligent Transportation Systems for Wireless Sensor Networks Based on ZigBee. Proceedings of International Conference on Computer and Communication Technologies in Agriculture Engineering (CCTAE2010), 2, 396-399.

[19] Katiyar, V., Kumar, P. and Chand, N. (2011) An Intelligent Transportation Systems Architecture Using Wireless Sensor Networks. International Journal of Computer Applications, 14, 22-26. http://dx.doi.org/10.5120/1816-2369

[20] Selvarajah, K., Shooter, C., Liotti, L. and Tully, A. (2011) Heterogeneous Wireless Sensor Network for Transportation System Applications. Hindawi Publishing Corporation International Journal of Vehicular Technology. 2011, Article ID: 853948. http://dx.doi.org/10.1155/2011/853948 
[21] Selvarajah, K., Arief, B., Tully, A. and Blythe, P. (2012) Deploying Wireless Sensor Devices in Intelligent Transportation System Applications. Intelligent Transportation Systems, InTech, Rijeka.

[22] Karpis, O. (2013) Wireless Sensor Networks in Intelligent Transportation Systems. International Journal of Modern Engineering Research (IJMER), 3, 611-617.

[23] Warriach, E. and Claudel, C. (2013) A Machine Learning Approach for Vehicle Classification Using Passive Infrared and Ultrasonic Sensors. Proceedings of 12th International ACM Conference on Information Processing in Sensor Networks (IPSN). Philadelphia, 08-11 April 2013, 333-334. http://dx.doi.org/10.1145/2461381.2461434

[24] Masarak - Traffic-Enabled Services Project (2014) Qatar Mobility Innovation Center. http://www.masarak.com

[25] Hawa’ak-Environment Monitoring System Project. Qatar Mobility Innovation Center http://www.qmic.com/solutions/smart-living-services/environment-monitoring-system

[26] Labeeb_-Intelligent Sensing and M2M Platform (2014) Qatar Mobility Innovation Center. http://www.qmic.com/solutions/intelligent-sensing-and-m2m-platform

[27] Dash—Smarter Driving Every day (2014) http://dash.by

[28] Dai, J.J. and Song, H. (2011) Design and Realization of CAN Bus Vehicle Instrument Cluster Based on $\mu$ C/OS-II. Proceedings of 2nd International Conference on Mechanic Automation and Control Engineering (MACE), Hohhot, 15-17 July 2011, 1159-1161.

[29] Safe Road Trains for the Environment (SARTRE) (2014) EU-Funded Project. http://www.sartre-project.eu 
Scientific Research Publishing (SCIRP) is one of the largest Open Access journal publishers. It is currently publishing more than 200 open access, online, peer-reviewed journals covering a wide range of academic disciplines. SCIRP serves the worldwide academic communities and contributes to the progress and application of science with its publication.

Other selected journals from SCIRP are listed as below. Submit your manuscript to us via either submit@scirp.org or Online Submission Portal.
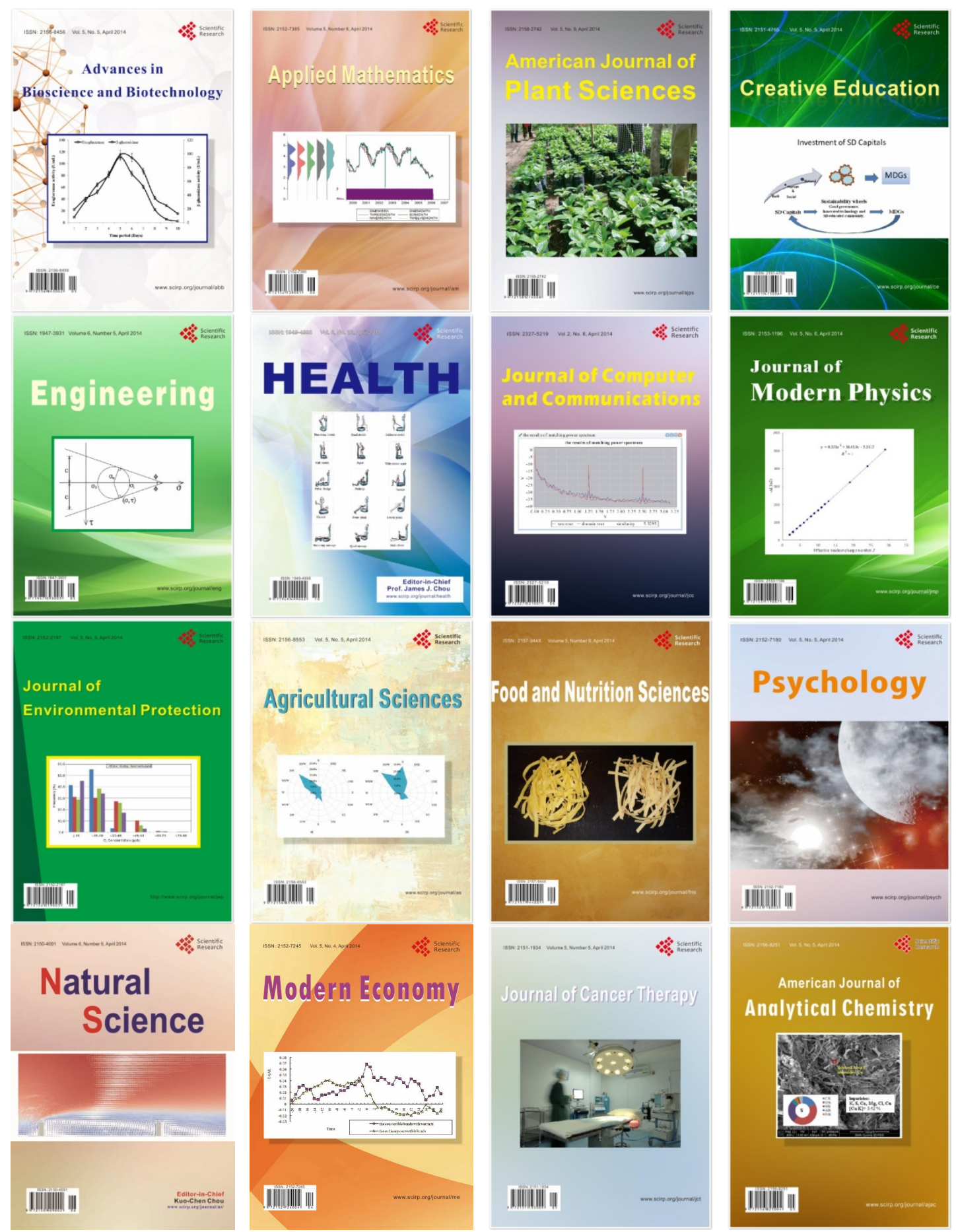